\title{
Algunas variables que influyen en las representaciones de género en el Poder Judicial de Chile*
}

Some variables that influence gender perceptions in the Chilean

Judicial Branch of the State

Pablo Fuentealba Carrasco ${ }^{1 \otimes}$, Gabriela Sánchez Pezo ${ }^{2 \otimes}$, Ximena Gauché Marchetti ${ }^{3 凶}$ Daniela Santana Silva ${ }^{4}$, Valentina Rioseco Vallejos ${ }^{5 \boldsymbol{\Delta}}$, Cynthia Sanhueza Riffo ${ }^{\mathbf{\Delta}}$ Rodrigo González Fuente ${ }^{7 \boldsymbol{\Delta}}$, Álvaro Domínguez Montoya ${ }^{8 \boldsymbol{\Delta}}$, Cecilia Bustos Ibarra ${ }^{\mathbf{\Delta}}$

Cecilia Pérez Díaz ${ }^{10}$, Manuel Barria Paredes ${ }^{11} \boldsymbol{\Delta}$

Fecha correspondencia:

Recibido: 25 de noviembre de 2019.

Revisión: 4 de marzo de 2020.

Aceptado: 25 de marzo de 2020.

Forma de citar:

Fuentealba, Pablo; Sánchez,

Gabriela; Gauché, Ximena; Santana,

Daniela; Rioseco, Valentina;

Sanhueza, Cynthia; González-

Fuente, Rodrigo; Domínguez,

Álvaro; Bustos, Cecilia; Pérez,

Cecilia; Barria, Manuel. "Algunas

variables que influyen en las

representaciones de género en el

poder judicial de Chile." Revista

CES Derecho. Vol. 11, №. 1, enero a

junio de 2020, 28-54.

Open access

Términos de uso

Licencia creative commons

Ética de publicaciones

Revisión por pares

Gestión por Open Journal System

DOl: http://dx.doi.org/10.21615/

cesder.11.1.2

ISSN: 2145-7719

Sobre el artículo:

El artículo de investigación científica y tecnológica. Se enmarca dentro del Proyecto

\section{Resumen}

Los problemas asociados a estereotipos, discriminación y brecha de género, atraviesan a las diversas instituciones sociales, incluidas aquellas encargadas de administrar justicia. El artículo buscó conocer si el perfil sociodemográfico, el escalafón de pertenencia, variables de género y las características del tribunal de trabajo influyen en las representaciones de género en el PJUD. El tema es relevante en el marco de los compromisos internacionales de DDHH adquiridos por Chile y de la Política de igualdad de género y no discriminación del PJUD.

Palabras clave: Estereotipos de género; discriminación por género; roles de género; igualdad de género; Poder Judicial.

\section{Abstract}

Problems linked with stereotypes, discrimination and inequality due to gender, are present in a variety of social institutions, including those responsible to administering justice. The article sought to know whether if sociodemographic features, the labor rank, gender variables and the characteristics of the labor court influence gender representations within the Chilean Judicial Branch. The issue is relevant within both, the framework of the International Human Rights commitments acquired by Chile, and the gender equality and non-discrimination policy of the PJUD.

Keywords: Gender stereotypes; gender discrimination; gender roles; gender equality; Chilean Juridical Branch.

\section{Introducción}

La igualdad de género es un principio fundamental protegido por el derecho internacional de los derechos humanos ${ }^{1}$. De éste emana, para los Estados suscrito -entre ellos Chile-, la obligación negativa de abstenerse

1. Artículo 3, común del Pacto Internacional de Derechos Civiles y Políticos, y del Pacto Internacional de Derechos Económicos, Sociales y Culturales y Convención sobre la eliminación de todas las formas de Discriminación contra la mujer (CEDAW). Articulo 24 Convención Americana de Derechos Humanos. 
FONDEF ID $17 / 10111$

"Protocolo de actuación

para la atención en justicia

con enfoque de género y

diversidad", 2018-2020.

Además, agradecemos a

la Excma. Corte Suprema

de Justicia de Chile y

a la Secretaría Técnica

de lgualdad de Género

y No Discriminación por

proporcionar la base

de datos de su estudio

"Estudio Diagnóstico de la

perspectiva de igualdad

de género" que fueron

generados por la con

cultura Managment \&

Research. Con estos datos

efectuamos los análisis.

\section{Sobre los autores:}

1. MA en Investigación

Social y Desarrollo. Prof.

Asistente del Dpto. de

Sociología, Universidad de

Concepción, Concepción

Chile.

2. Socióloga. Dpto. de

Sociología, Universidad de

Concepción, Concepción

Chile. Apoyo investigación,

Proyecto FONDEF,

Universidad de Concepción,

Chile.

3. Dra. en Derecho,

Universidad Autónoma

de Madrid, España. Prof.

Asociada, Facultad de

Cs. Jurídicas y Sociales,

Universidad de Concepción,

Chile.

4. LL.M en estudios

avanzados de Derecho

Internacional Público,

Universidad de Leiden.

Apoyo investigación,

Proyecto FONDEF,

Universidad de Concepción,

Chile. de discriminar por género y la obligación positiva de adoptar las medidas necesarias para respetar y garantizar este derecho².

En materia de la brecha de género, Chile ha pasado desde el puesto 70 en el 2016 al 54 en el 2018, ubicándose en el promedio latinoamericano (Datos Macro, 2018). Sin embargo, la pervivencia de esta brecha aún perjudica los derechos y oportunidades de las mujeres (Arriagada, 2005, pg.101-113) en muchos espacios donde no son protagonistas ni pueden gozar del empoderamiento y de la igualdad (Instituto Nacional de Estadísticas, 2013; Gauché et.al, 2016, pg.159). Por ejemplo, las mujeres con estudios superiores obtienen un $35 \%$ menos de salario que el recibido por hombres que realizan una misma labor (Programa de las Naciones Unidas para el Desarrollo, 2016). Además, en el 2009, Chile era uno de los cuatro países con menos mujeres en directorios públicos y privados, lo cual cambió significativamente para el año 2015 (La Tercera, 2016). Esto evidenciaría que los avances han sido positivos pero insuficientes y se han mirado tradicionalmente con ojos masculinos desde una sociedad patriarcal y sexista (Gauché et. al, 2016, pg.165).

Las administraciones judiciales no son ajenas a estos problemas e intentos de solución. Así, en Latinoamérica, la participación femenina ha aumentado significativamente en los máximos tribunales de justicia, lográndose un incremento de 5,8 puntos porcentuales entre el 2007 y 2017 (CEPAL, 2017). En Chile, las cifras actuales del Poder Judicial (PJUD), muestran que hay un 37.9\% de magistradas mujeres en la Corte Suprema y un $54,9 \%$ en las Cortes de Apelaciones. En tribunales pequeños y medianos esta cifra asciende a un $53,6 \%$ y en tribunales grandes a un 67,2\% (Poder Judicial de Chile, 2018). Por otro lado, desde el 2014 la Academia Judicial de Chile ha ampliado la oferta formativa en materia de igualdad, no discriminación, género y diversidad sexual como una posible solución (Academia Judicial, 2016). Estas cifras generales reflejan que Chile viene dando constantes pasos y pruebas de voluntad estatal para atenuar las desigualdades de género, sobre todo en los organismos estatales como lo es el PJUD (Secretaría Técnica de Género y no Discriminación, 2018 a).

La tendencia positiva en la corrección de la desigualdad y brecha de género no ha liberado al PJUD de la existencia de estereotipos de género, creencias o prácticas que aún perjudican a mujeres. Muchas de estas prácticas fueron identificadas por el Estudio Diagnóstico con Enfoque de Género y Diversidad en el Poder Judicial (Dirección de Estudios Corte Suprema, 2016) -en adelante Estudio Diagnóstico-, siendo el primer estudio -mediante encuesta online a 4400 funcionarios/as- en esta materia realizado al interior de este poder del estado. Se encontró que un 11,3\% declaró haber sido acosado/a o presenciado acoso, y se identificó la presencia de creencias naturalizadas sobre los roles que deben cumplir las mujeres y sobre sus capacidades. Por ejemplo, un $38 \%$ cree que las áreas de familia y crianza son más apropiadas para las mujeres que para los hombres. Un $44 \%$ de los/as encuestados/as piensa que, dependiendo del cargo ocupado, mujeres y hombres no tienen el mismo desempeño. Además, se observó que un 30,6\% de los funcionarios reconoce la existencia roles laborales diferenciados por género (Dirección de Estudios Corte Suprema, 2016, pg.90). Esto reflejaría que estas representaciones de género, aún persisten.

Hechos contextuales bastante claros han empujado al PJUD a buscar transformaciones para disminuir las brechas y prácticas discriminatorias en materia de género y diversidad sexual. El caso Karen Atala ha sido fundamental en este sentido, ya que llevó a que el Estado de Chile fuese condenado por la Corte IDH, exigiéndose

2. Comité de Derechos Humanos (CDH), Observación general No. 28, Comité de Derechos Económicos, Sociales y Culturales (CDESC), Observación Genera No. 16, Atala Riffo y Niñas v Chile, Corte Interamericana de Derechos Humanos, párrafo 82. 
5. MA en Derechos Humanos, Universidad de Edinburgh. Apoyo investigación, Proyecto FONDEF, Universidad de Concepción, Chile.

6. Lic. en Educación.

Colaboradora técnica,

Proyecto FONDEF,

Universidad de Concepción, Chile.

7. Dr. en Derecho, Universidad de Göttingen. Prof. Asociado, Facultad de Cs. Jurídicas y Sociales, Universidad de Concepción, Concepción, Chile.

8. MA en Drets Sociolaborals, Universidad Autónoma de Barcelona. Prof. Asociado, Facultad de Cs. Jurídicas y Sociales, Universidad de Concepción, Concepción Chile.

9. Dra. en Sociología. Prof Asistente del Dpto. de Trabajo Social, Facultad de Cs. Sociales, Universidad de Concepción, Concepción, Chile.

10. MA en Trabajo Social y Políticas Sociales. Prof. Asociada, Facultad de Cs. Sociales, Universidad de Concepción, Concepción, Chile.

11. Dr. en Derecho, Pontificia Universidad Católica. Prof. Asociado, Facultad de Cs. Jurídicas y Sociales, Universidad de Concepción, Concepción, Chile. entre otras cosas, la incorporación de la perspectiva de género y diversidad en el PJUD (Atala Riffo y Niñas vs Chile, 2012). A nivel nacional, el caso Gabriela Blass puso en discusión las exigentes expectativas sociales de rol como cuidadoras y su interseccionalidad con lo étnico (Gabriela Blass y su hija CBB, 2018). Los casos de Daniel Zamudio y Wladimir Sepúlveda abrieron una discusión sobre los criterios de administración de justicia carentes de perspectiva en diversidad sexual (Muñoz, 2015, pg.1-23), así como la necesidad de legislar.

Sin embargo, mejoras en este sentido requieren de una comprensión más profunda del fenómeno de género, que vaya un poco más allá de los hallazgos otorgada por el Estudio Diagnóstico. Por ello, el presente artículo tiene como objetivo identificar los factores que influyen en las representaciones de género en el PJUD. Esta información resulta valiosa si se comprende a la luz del marco normativo internacional y nacional y, principalmente, a la luz de la Política de género y no discriminación del PJUD del 2018.

En ese contexto, como parte de una investigación aplicada sobre atención de justicia con enfoque de género y diversidad, hemos efectuado un nuevo análisis de los datos del Estudio Diagnóstico de la Perspectiva de Género en el Poder Judicial (proporcionados por el PJUD) desde un marco teórico que presenta conceptos y modelos explicativos centrales para orientar esta investigación.

\section{Género, machismo y patriarcado}

A diferencia del sexo (diferencias biológicas entre hombres y mujeres), el género refiere a la construcción psicológica, cultural y social de la sexualidad (Lamas, 1999, pg.327-331; Facio, s.a, pg.7-12; Benavente \& Vergara, 2006, pg.107-111). Que el género sea construido significa que las representaciones que tenemos acerca de lo masculino o femenino, las expectativas de rol -comportamiento socialmente esperado para un hombre o mujer-y la conducta, no están determinados biológicamente. Más bien, corresponde a un orden construido sobre lo que culturalmente se considera ser hombre o mujer (Arena, 2016, pg.52-56; Asociación de Magistradas Chilenas, 2015, pg. 9-11; Bruel Dos Santos, 2008, pg.9-10) y que se transmiten y refuerzan a través del proceso de socialización, que enseña la cultura desde una generación a otra las nociones acerca de lo masculino y femenino (Fuller, 2012, pg.117-123), donde intervienen la familia, la religión, los medios de comunicación entre otros agentes (Arenas, 2016; Facio,s.a). La exposición continua a estos mensajes culturales, lleva a la naturalización del género, es decir, que las personas lo consideren como un orden natural, lógico y obvio, olvidando que son construcciones institucionalizadas (De Barbieri, 1993, pg.145-166; Fuller, 2012, pg.117-123), influyendo en el sentir y actuar de las personas. Por ejemplo, las mujeres pueden ser discriminadas en su acceso a puestos de jefatura porque se cree que son naturalmente más emocionales que los hombres y no pueden tomar decisiones racionales (Etchezahar \& Ungaretti, 2014, pg.87-94).

En la mayoría de las sociedades, la construcción del género parte con la división sexual y estratificada del trabajo, que relegó a las mujeres al ámbito privado o doméstico, a actividades ligadas a su función reproductiva y de cuidado. En cambio, los hombres se definieron como aptos para la esfera pública, y a los roles de proveedor y supervivencia (Chávez, 2004 en Trejo, 2017, pg.137). También se ha desarrollado una visión de género que históricamente asocia lo masculino a la fuerza, resistencia e inteligencia, mientras que lo femenino se vincula a sentimientos, empatía y cuidados (Jociles, 2001, pg.1-11) generándose la imagen de debilidad de la mujer. 
Históricamente, estas imágenes asociadas al género, han generado jerarquías, relaciones de superioridad e inferioridad, asimetría de poder y prestigio social, siendo las mujeres las más afectadas y objeto, muchas veces, de menosprecio y/o discriminación por el sólo hecho de ser mujeres (Osorio, 2015, pg.134), afectando su desarrollo como personas y sus derechos en la sociedad. El patriarcado (sistema social caracterizado por la dominación de los hombres) y el machismo (actitudes o formas de pensar que consideran que el hombre es superior) reflejan estos aspectos (Fuller, 2012, pg.117-123; Facio, s.a).

\section{Consecuencias del sistema sexo-género}

Las mujeres enfrentan adversidades laborales (Morales, 2016, pg.71-74; Macionis \& Plumer, 2007; Mendoza et. al, 2017, pg.103-109; Vargas et. al, 2015, pg.651-654). Existe un trabajo no remunerado que constituye una carga adicional para las mujeres y que afecta su dimensión laboral (CEPAL, 2016). Así, las actividades domésticas y de crianza -que no posee la mayoría de los hombres- dificultan la disponibilidad de las mujeres para trabajar (Vargas et al, 2015, pg.651-654; Arredondo et. al, 2013, pg.161-166). A esto se suma la diferencia salarial sustancial entre hombres y mujeres (Mendoza et.al, 2017, pg.103-109; Cacciamali \& Tatei, 2013, pg.55-57), las dificultades para ascender de puesto y la discriminación en contrataciones a mujeres en edad fértil por las consecuencias económicas y prácticas que los empleadores creen que tendrán por contratarlas (Arredondo et. al, 2013, pg.161-166). Las víctimas de acoso sexual en el trabajo son en su mayoría mujeres (Herrera et al, 2014, pg. 2-7; Hernández et. al, 2015, pg.64-70), práctica que se origina principalmente en la creencia de que éstas son el sexo débil (Hernández et. al 2015, pg.64-70; Herrera et. al, 2017, pg.2-7) o de que el hombre tiene el derecho a controlar la sexualidad femenina (Fuller, 2012; Facio, s.a; Lamas, s.a). Esto muestra que las imágenes sobre género no son inocuas, sino que influyen en el comportamiento social.

Estudios muestran que $88 \%$ de las encuestadas afirma haber sido discriminada en el trabajo y un 69\% afirma que existen más oportunidades para hombres que para mujeres (Centro Regional de Derechos Humanos y Justicia de Género, 2017, pg.6-22). Pero las percepciones de discriminación no son socio-demográficamente homogéneas. Las mujeres perciben más discriminación y acoso que los hombres, por ser las víctimas directas del sistema sexo-género. Por ello, la mujer directiva, generalmente tiene mejor disposición que los hombres para apoyar la flexibilidad laboral, permitiendo elecciones de horario y fórmulas de trabajo para que mujeres puedan cumplir su responsabilidad social impuesta del cuidado del hogar (Facio, s.a; Saldivia, s.a, pg.98-119). Esto se explica principalmente desde la experiencia vivida de trabajar y ser mujer, y porque las mujeres tienden a considerar más las necesidades de los otros en sus decisiones para equilibrar trabajo y familia (Arredondo, et. al, 2013, pg.161-165).

La discriminación laboral que viven las mujeres deriva de los estereotipos y expectativas de rol asociados al género, así como de aspectos biológicos (Dirección de Estudios Corte Suprema, 2016), ya que en el caso de la maternidad y los derechos sociales que esto conlleva, también se evidencia discriminación. En el 2011 en el PJUD se comenzó a aplicar la ley 20.545 que otorga un permiso voluntario de 12 semanas adicionales al post natal para mitigar el problema de la ausencia de apego y amamantamiento. Sin embargo, el uso de este beneficio redujo a un tercio sus emolumentos mensuales y/o la rebaja del bono anual de cumplimiento de metas por no contabilizarse los días de permiso como días trabajados en juezas. Esto se tradujo en renuncias al beneficio para mantener el salario completo, perdiéndose el objetivo 
de la ley (Álvez, 2008, pg.217-229). Sumado a esto, el Estudio Diagnóstico identificó la discriminación social a la mujer basada en roles y estereotipos de género. En la pregunta ¿Han experimentado y observado algún trato discriminatorio?, un $42 \%$ de las mujeres señala haber sido asignada a puestos de menor valoración y un $25 \%$ reconoce la existencia de discriminación por ser padre/madre (Dirección de Estudios Corte Suprema, 2016, pg.147), dando cuenta de una discriminación directa basada en la condición de madre, y de una discriminación laboral por ser mujer.

Otros estudios han evidenciado diferencias en la percepción de discriminación por edad y nivel socioeconómico (NSE). Así, el porcentaje de mujeres que se siente discriminada es de un $79,3 \%$ en personas de 18 a 30 años, de un $86,6 \%$ en personas de entre 31 y 40 años, de un $83 \%$ en el tramo de 41 a 60 años, y de $77 \%$ en personas mayores de 61 años, lo cual reflejaría una tendencia de parábola. Las mujeres pertenecientes a un NSE alto identifican mayor discriminación general en un 93,6\%, las pertenecientes a un NSE medio en un $81,6 \%$ y las pertenecientes a un nivel bajo en un 80,3\% (Centro Regional de Derechos Humanos y Justicia de Género, 2017, pg.6-22), revelándose una mayor percepción de discriminación cuando mejora el NSE.

\section{Políticas y normativa en los poderes judiciales de Latinoamérica y Chile}

En Latinoamérica han surgido instancias que buscan incorporar la igualdad de género en el quehacer judicial. En la década del 2000 se crearon las comisiones nacionales de género en Costa Rica (2001), El Salvador (2006), Colombia (2008), República Dominicana (2008) y Argentina (2009). En la década del 2010 se formaron direcciones de equidad y secretarías de género en Paraguay (2010), México (2015) y Uruguay (2016). En todas estas unidades se trabaja con ministras, magistradas y/o juezas, además de profesionales de ciencias sociales para promover la institucionalización, formación e información en la perspectiva de género, realizar estudios, proponer políticas y planes de acción para asegurar la igualdad y no discriminación hacia mujeres, y evaluar el cumplimiento de esos planes (Gobierno de Chile, 2018). Se destaca que, regularmente, estos objetivos han nacido y estado a cargo de la Corte Suprema de justicia de cada país. Esto denota que la preocupación por este tema se ha presentado verticalmente, desde los poderes centrales de justicia.

En Chile, esta tendencia se expresa con la creación de la Asociación Nacional de Magistradas en 2013. Su objetivo es la defensa y promoción de los derechos de las mujeres conforme al derecho nacional e internacional, considerando el compromiso de justicia, igualdad y el Estado de derecho como pilares de una república democrática Asociación de Magistradas Chilenas, 2015). En el 2017 se creó la Secretaría de Género del PJUD orientada a diagnosticar e implementar políticas de este tipo (Secretaría Técnica de Género y no Discriminación, 2018b). Debe precisarse que, aunque en Chile la Corte Suprema ha promovido verticalmente la incorporación del enfoque de género y diversidad, el impulso más importante se origina en el pronunciamiento internacional dado por la Corte IDH en el ya mencionado caso Atala (Atala Riffo y niñas vs. Chile, 2012).

Por otra parte, Chile es parte de tratados de Derechos Humanos y Declaraciones, vinculantes y no vinculantes que consagran el derecho a la igualdad y la no discriminación. Respecto de la legislación vinculante, Chile se ha comprometido a cumplir con la obligación de adoptar todas las medidas necesarias para garantizar y promover este derecho y con la obligación de no discriminar por género. Tratándose de la 
normativa internacional, Chile ratificó el Pacto Internacional de Derechos Civiles y Políticos (PIDCP) y el Pacto Internacional de Derechos Económicos Sociales y Culturales (PIDESC), que consagran el principio a la igualdad y la prohibición de discriminación en su artículo 3 común. Más aún, ratificó el Primer Protocolo Opcional del PIDCP otorgando competencia al Comité de Derechos Humanos (CDH) para conocer de comunicaciones individuales respecto de violaciones a los derechos protegidos por el PIDCP. Además, ratificó la Convención sobre la Eliminación de Todas las Formas de Discriminación contra la Mujer ${ }^{3}$ (CEDAW, por sus siglas en inglés) y su Protocolo Opcional, que también le reconoce competencia al comité CEDAW para conocer de violaciones a los derechos protegidos en dicha convención.

También, Chile es parte de la Convención Americana de Derechos Humanos, que reconoce en su artículo 24 la igualdad ante la ley y el derecho, sin discriminación. Además, reconoció competencia a la Corte IDH que protege a través de una función contenciosa y una consultiva el cumplimiento de estos derechos cuando son violados. Asimismo, ratificó la Convención Interamericana para Prevenir, Sancionar y Erradicar la Violencia contra la mujer Belém do Pará4.

Los instrumentos no vinculantes contribuyen a interpretar las formas de cumplimiento de las obligaciones antes presentadas (Poder Judicial de Chile, 2018b). Aquí destaca la Declaración y Plataforma de Acción de Beijing del año 1995, y los principios de Yogyakarta ${ }^{5}$. Siguiendo esta línea, tanto la Corte como la CIDH se han pronunciado en materia de derechos humanos y mujeres, reiterando el derecho de protección igualitaria y de no discriminación. En el 2017 la Corte IDH hizo pública la opinión consultiva $24 / 17$ sobre identidad de género, igualdad y no discriminación (Corte Interamericana de Derechos Humanos, 2017), siendo un aporte a la comprensión de esta realidad.

En el ámbito interno, el derecho a la igualdad y la prohibición de discriminación se encuentran incorporados en lo dispuesto en el artículo 5 inciso 2 de la Constitución Política de la República. Al ser un derecho esencial que emana de la naturaleza humana, reconocido en tratados internacionales ratificados por Chile y vigentes, este Derecho constituye un límite a la soberanía nacional, siendo deber de los Estados respetarlo y promoverlo. A ello se suma la obligación positiva emanada del artículo 2 de la Convención Americana de Derechos Humanos, en virtud de la cual los Estados son llamados a adoptar su propia legislación interna para el efectivo cumplimiento de los derechos protegidos en ella, avanzándose legislativamente en Chile durante los últimos años. Por ejemplo, en la década de los 90' se crea el Servicio Nacional de la Mujer (Ley N¹9023, 1991) y se modifica el Código del Trabajo en materia de protección a la maternidad (Ley $\left.N^{\circ} 19.1591,1998\right)$. En la década del 2000 se implementan normativas de maternidad y cuidado (Ley $N^{\circ} 20.166,2007$; Ley $N^{\circ} 20.255,2008$; Ley $N^{\circ} 20.348$, 2009), de igualdad en remuneraciones para hombres y mujeres por la misma labor (Ley $N^{\circ} 20.348,2009$ ), se crea la ley de Violencia (Ley $\left.N^{\circ} 20.066,2005\right)$ y se tipifica y sanciona el Acoso Sexual (Ley N²0.005, 2005). Desde el 2010 se ha presentado un avance legislativo mayor en materia de género y no discriminación, a nivel familiar (Ley $N^{\circ} 20.480,2010$; Ley $N^{\circ} 20.830,2015$; Ley $N^{\circ} 20.891,2016$; Ley $N^{\circ} 20.545$, 2011), maternal/paternal (Ley $N^{\circ} 21.063,2017$; Ley $N^{\circ} 21129,2019$ ), en torno a la mujer y la reivindicación de sus derechos (Ley N²0.820, 2015; Ley N²0.595, 2012; Ley $\left.N^{\circ} 20.820,2015\right)$, a la discriminación (Ley N²0.609, 2012), identidad sexual (Ley

3. Aprobada por la Asamblea General de las Naciones Unidas en 1979 y ratificada con declaración por Chile el 7 de diciembre de 1989.

4. Aprobada en el Vigésimo Cuarto periodo ordinario de sesiones de la Asamblea General de la Organización de los Estados Americanos el 6 de septiembre de 1994, ratificada por Chile el 15 de noviembre de 1996

5 Los principios de Yogyakarta contienen principios sobre la aplicación de la legislación internacional de derechos humanos en relación con la orientación sexual y la identidad de género. 
$N^{\circ} 21.120,2018$ ), sexualidad (Ley $N^{\circ} 20.418,2010$; Ley $N^{\circ} 20.533,2011$ ) y aborto (Ley N²1.030, 2017). Esto muestra que las políticas públicas y legislativas apuntan en la misma dirección que los esfuerzos del PJUD y su política de igualdad de género y no discriminación, además de un compromiso para avanzar hacia un modelo de justicia inclusivo y respetuoso de la diversidad, con miras a un efectivo acceso a la justicia (Poder Judicial de Chile, 2018b).

A pesar de la existencia de políticas y legislaciones como las mencionadas, las prácticas y representaciones sexistas, las expectativas de rol y estereotipos de género en el PJUD siguen presentes (Dirección de Estudios Corte Suprema, 2016; Álvez, 2008) aunque no necesariamente de forma homogénea. Como ya mencionamos, las políticas de género y su cumplimiento son creadas y monitoreadas desde las grandes cortes y altas jefaturas. Por ello, dada la naturaleza jurídica y el impacto del caso Atala, podría pensarse que el tema de género y diversidad se encuentra más incorporado en jueces y ministros antes que en otras jerarquías. Además, el tamaño del grupo social puede influir en los vínculos sociales existentes en la comunidad (Lorenc, 2014, pg.299-308). Según la teoría Durkheimiana, en comunidades pequeñas, existen prácticas similares entre los individuos y una moralidad común más fuerte con poca diversidad, lo cual genera mayor unidad. La transgresión a la norma o tradición puede verse como una amenaza para el colectivo. En colectivos de mayor tamaño hay un debilitamiento de este vínculo social (o también cohesión), con un consenso moral más débil, lo cual se ha entendido también como la distinción entre Gesellschaft o sociedad y Gemeinschaft o comunidad (Rodríguez \& Costa, 2013, pg.115-120). Con ello, podría preverse que organizaciones más pequeñas en tamaño podrían ser más tradicionales en sus valores.

En Latinoamérica es difícil encontrar investigaciones que incorporen aspectos de género en ámbitos judiciales. En Chile, en lo referente a estudios sobre representaciones de género, sólo se cuenta con el Estudio Diagnóstico (Dirección de Estudios Corte Suprema, 2016), que es eminentemente descriptivo, y no identifica los factores que influyen en representaciones de género. Por ello, esta investigación busca conocer si las representaciones de género de quienes trabajan en el PJUD ('percepción de machismo explícito', 'visión sobre desempeño y las capacidades igualitarias de género en el ámbito laboral' y 'expectativa de desempeño igualitario entre hombres y mujeres para labores de justicia al interior del PJUD') son influidas por aspectos sociodemográficos (p.ej. sexo, edad, nivel educacional), variables de género (p.ej. el percibir hostigamiento laboral con contenido sexual en el lugar de trabajo, el haber sido discriminado/a por ser hombre o mujer, etc.), el escalafón de pertenencia (p.ej. ser juez/a o ministro; ser otro tipo de profesional, etc.) y/o las características de la unidad laboral a la cual pertenecen (porcentaje de magistradas en la unidad de trabajo, tamaño de la corte, el trabajar o no en la Corte Suprema). Para el objetivo propuesto, hemos reanalizado la base de datos que se utilizó para desarrollar el Estudio Diagnóstico.

La literatura científica en esta temática es escasa, y pocos estudios abordan objetivos similares, en contextos también similares. Sin perjuicio de esto, nos hemos aventurado a proponer algunas hipótesis investigativas. Postulamos que personas con mayores niveles de machismo percibido, que poseen una visión más igualitaria sobre desempeños y capacidades y/o sobre expectativas sobre el desempeño laboral entre hombres y mujeres en el PJUD serían:

- Mujeres, personas de menor edad, personas con mejores niveles educacionales, personas con relaciones de parejas y con hijos. 
- Personas pertenecientes al Escalafón Primario y Escalafón Secundario del Poder Judicial chileno.

- Personas que han experimentado o presenciado hostigamiento laboral con contenido sexual, quienes han presenciado o experimentado acoso sexual laboral, quienes poseen expectativas equitativas de rol de género (en la sociedad), quienes han recibido una formación en temas de género, quienes han sido discriminadas por ser mujeres y quienes no han sido discriminados por ser hombres.

- Personas que prestan sus labores en la Corte Suprema, quienes trabajan en las cortes de apelaciones de mayor tamaño, y quienes trabajan en cortes de apelaciones con un mayor porcentaje magistradas (mujeres).

\section{Metodología}

El estudio fue cuantitativo y explicativo, ya que buscamos identificar los factores que influyen en las representaciones de género en el PJUD. Los datos provienen del Estudio Diagnóstico del PJUD, se recogieron en 2015 mediante un cuestionario online autoaplicado. El que los datos no hayan sido generados por nosotros, es una de las principales limitaciones del estudio, ya que hubo preguntas que hubiésemos estimado pertinentes de formular y que no fueron incluidas, otras que hubiésemos planteado de forma distinta o con diferentes opciones de respuesta para facilitar los análisis estadísticos. Fue necesario realizar un trabajo de depuración de los datos e identificación selectiva de aquellas preguntas que podían ser incluidas en el análisis (se encontraban claramente formuladas, poseían sentido teórico, etc.), mientras que un alto número de ítems fue excluido por no cumplir con mínimos estándares metodológicos.

\section{Muestra}

El cuestionario estuvo dirigido a funcionarios/as de todos los escalafones del PJUD: Primer Escalafón (jueces/as de tribunal ordinario y Secretario/as ${ }^{6}$ de Juzgado; ministros/ as de las cortes de apelaciones y de la Corte Suprema), Segundo Escalafón (administradores de tribunal, jefes de unidad y consejeros técnicos tales como psicólogos/as y trabajadores/as sociales), Escalafón de Empleados (Administrativos, Oficiales, Secretarias ejecutivas, etc.) y personal a honorarios y a contrata. No participaron personas que intervienen en el Poder Judicial, pero que administrativamente no pertenecen a él (p.ej. defensores, fiscales, abogados litigantes).

Dado que el cuestionario podía responderse voluntariamente -sin una selección aleatoria-, la muestra se consideró como no-probabilística. Su tamaño fue de 4.292 casos, sobre un universo de 11.959 funcionarios/as, lo cual representa una tasa de respuesta de un $36,4 \%$. Un $55 \%$ de las encuestadas fueron mujeres, un $19,3 \%$ se encuentra entre los 18 y 34 años de edad, un 55,9\% se encuentra entre los 35 y 49 años y un $24,8 \%$ tiene más de 50 años. Un 13\% de los/as encuestados/as pertenece al Escalafón Primario, un 13,1\% pertenece al Escalafón Secundario, un 48\% al Escalafón de empleados/as y un $25,8 \%$ es trabajador/a a contrata u honorarios, de todas las zonas del país.

Dada la muestra, tenemos la limitación de que no es posible generalizar los resultados estimando el margen de error. Sin embargo, el gran tamaño muestral y la heterogeneidad (geográfica y sociodemográfica) de la muestra permiten pensar que los resultados reflejarían en buena medida la tendencia y que son adecuados para efectuar análisis que relacionen variables.

6. En Chile el/la Secretario/a de Juzgado es un juez no titular. 


\section{Variables}

Una variable es una propiedad susceptible de presentar variaciones o distintos valores entre un individuo y otro (por ejemplo, la edad, el sexo de una persona, su opinión). Son la materia prima usada en las ciencias sociales que buscan medir, describir o relacionar variables. Tenemos variables independientes (variables causales o que influyen) y dependientes (variable "efecto" que se busca explicar mediante las independientes):

\section{Variables dependientes}

e construyeron tres variables dependientes que fueron: 1) Machismo percibido explícitamente en el PJUD, que alude al grado en que el individuo percibe que dentro del PJUD existe una cultura patriarcal y machista desde en las relaciones laborales y sociales. Se elaboró con la combinación de 2 preguntas. Luego, tenemos 2) la Visión sobre el desempeño y las capacidades igualitarias entre hombres y mujeres en el ámbito laboral (en general), que refiere al grado en que el individuo considera que hombres y mujeres poseen capacidades iguales (o desiguales) para desempeñarse en el ámbito laboral (y no únicamente en ámbitos relacionados con el Derecho), y que se elaboró con el promedio de 6 preguntas. Finalmente, tenemos 3) Expectativa sobre desempeño igualitario entre hombres y mujeres para labores de justicia que es el grado en el que el individuo considera que hombres y mujeres tienen -o no- iguales capacidades para desempeñarse en diferentes funciones y áreas del Derecho al interior del PJUD, elaborada por la sumatoria de 12 preguntas. La obtención de bajos puntajes en las variables 2 y 3 , puede constituir, además, un indicador de sexismo.

La construcción de estas variables se fundamentó en un Análisis Factorial Exploratorio. La confiabilidad fue establecida mediante alpha (a) de Cronbach y permite conocer la precisión de la medición. Se encontraron valores cercanos o superiores a 0.7, lo cual indica que la fiabilidad es adecuada.

\section{Variables independientes}

Las variables independientes fueron clasificadas en cuatro bloques.

El primero corresponde al perfil sociodemográfico y condición civil. Incorpora el sexo, la edad y el nivel educacional del/la entrevistas. Además, incluye aspectos relativos a la condición civil, tales como tener o no tener pareja (que incluye matrimonio, conviviente, unión civil) y el tener o no hijos/as (tiene o no tiene hijos/as).

El segundo grupo de variables corresponde al escalafón del entrevistado en cuatro grupos. Considera al escalafón primario (Jueces/as y ministros/as), secundario (administradores/as de tribunal, consejeros/as técnicos/as, jefes/as de unidad), empleados (auxiliares, personal administrativo, oficial de sala entre otros) y personal a contrata u honorarios.

El tercer conjunto incluye a las variables de género. Corresponde a variables que guardan relación con aspectos de género, directa o indirectamente y que pueden influir en las percepciones de género. Incorpora el Hostigamiento laboral con contenido sexual (haber presenciado o sido víctima de diversas situaciones de hostigamiento sexual), acoso sexual (haber presenciado o sido víctima de acoso sexual) y discriminación de género (haber presenciado o sentirse discriminado por ser hombre o por ser mujer, que se tratan separadamente). Además, incluye a la expectativa equitativa de roles de género, que se entiende como medida en que los individuos entrevistados consideran que en la sociedad no existen roles naturales de género, ni una división sexual del trabajo por naturaleza, sino que hombres y mujeres pueden compartir los mismos 
roles y tareas. Finalmente, tenemos la formación en género, que se entiende como el haber asistido a cursos formales que contemplen contenidos de género.

Finalmente, las variables de contexto corresponden a aspectos más bien externos a la persona y que son, en este caso, de orden institucional. Tenemos aquí la pertenencia a la Corte Suprema, que indica si el entrevistado trabaja o no en la CS. Luego está el Tamaño de la Corte, que fue establecido en base al número de magistrados/as (ministros/as+jueces/as) por Corte, cuyo número oscila entre 16 y 357 magistrados/ as. Por último, tenemos el porcentaje de magistradas en la unidad de trabajo, que es una medida de presencia de mujeres en la Corte en la cual trabaja el entrevistado. Fue calculada en base al porcentaje de juezas y ministras presentes en cada Corte (valores oscilaron entre $25 \%$ y $67 \%$ de presencia femenina).

\section{Análisis}

Con estas variables se ejecutaron análisis descriptivos y explicativos. En el apartado siguiente exponemos los resultados descriptivos y explicativos sin incluir una interpretación teórica de los datos. En la sección siguiente (discusión) efectuamos dicha interpretación.

\section{Resultados}

\section{Resultados descriptivos}

Aquí exponemos los resultados descriptivos de las variables dependientes, que permiten conocer la distribución de los datos mediante el promedio, el porcentaje o la frecuencia entre otras medidas. La Tabla 1 describe los resultados de las 2 primeras variables estudiadas.

Tabla 1. Descriptivos para "Machismo percibido explícitamente en el Poder Judicial" y "Visión sobre el desempeño y las capacidades igualitarias en ámbito judicial"

\begin{tabular}{|c|c|c|c|}
\hline 1.-Machismo percibido explícitamente en el Poder Judicial & $\%$ Acuerdo & M & D.E \\
\hline $\begin{array}{l}\text { 1.1.-En el poder Judicial las jefaturas siempre han estado a cargo de } \\
\text { hombres }\end{array}$ & $20.4 \%$ & 2.49 & 1.11 \\
\hline 1.2.-El poder judicial tiene una cultura "machista" & $35.9 \%$ & 2.98 & 1.22 \\
\hline Totales & $28.1 \%$ & 2.73 & 1.17 \\
\hline $\begin{array}{l}\text { 2.- Visión sobre el desempeño y las capacidades igualitarias en ámbito } \\
\text { judicial }\end{array}$ & $\%$ Acuerdo & M & D.E \\
\hline 2.1.-Hombres y mujeres tienen diferentes estilos de liderazgo & $70.1 \%$ & 3.75 & 1.15 \\
\hline 2.2.-Mujeres y hombres tienen habilidades diferentes para el trabajo & $59.1 \%$ & 3.41 & 1.28 \\
\hline $\begin{array}{l}\text { 2.3.-Existen cargos más apropiados para mujeres y otros cargos más } \\
\text { apropiados para hombres }\end{array}$ & $31.8 \%$ & 2.70 & 1.29 \\
\hline $\begin{array}{l}\text { 2.4.-En algunas actividades laborales se desempeñan mejor las } \\
\text { mujeres y en otras lo hacen mejor los hombres }\end{array}$ & $44.9 \%$ & 3.05 & 1.30 \\
\hline 2.5.-No es conveniente contratar a mujeres en etapa reproductiva & $6.6 \%$ & 1.63 & 0.99 \\
\hline $\begin{array}{l}\text { 2.6.-En algunas materias jurídicas (Civil, penal, laboral) se } \\
\text { desempeñan mejor las mujeres y en otras mejor los hombres }\end{array}$ & $11.9 \%$ & 2.08 & 1.12 \\
\hline Totales & $37,4 \%$ & 2,77 & 1,19 \\
\hline
\end{tabular}

*Elaboración propia a partir de los datos del PJUD.

**Respuestas con 5 alternativas, desde Muy en desacuerdo (1) hasta Muy de acuerdo (5)

*** En la subescala machismo percibido en el PJ, valores cercanos a 5 indican que se percibe más machismo, y valores cercanos a 1 indican que percibe menos machismo. El 3.0 sería el valor de centro. En la subescala Visión de equidad en las relaciones laborales de género, valores cercanos a 5 indican que tiene una visión desigual en las relaciones de género, y valores cercanos a 1 indican que tiene una visión igualitaria. El 3.0 sería el valor de centro. 
La tabla muestra que, para la variable 1 , una minoría de los entrevistados $(28,1 \%)$ percibe la existencia de machismo al interior del PJUD. En la variable 2, las respuestas son algo más heterogéneas. Las visiones menos igualitarias en cuanto a desempeño y capacidades se encuentran en el estilo de liderazgo $(70,1 \%)$ y en habilidades para el trabajo en general $(59,1 \%)$, donde una mayoría considera que hombres y mujeres no tienen el mismo estilo o habilidades. Pero en los restantes 4 ítems restantes, existe una mayor visión igualitaria (bajo el 50\%) en cuanto a las capacidades. Una minoría, $37,4 \%$ tendría una visión poco igualitaria acerca de las capacidades para desempeñarse en el PJUD.

La tabla 2 muestra el porcentaje de entrevistados que posee expectativas igualitarias sobre el desempeño entre hombres y mujeres en labores de justicia.

Tabla 2. Descriptivos para "Expectativas sobre desempeño igualitario entre hombres y mujeres para labores de justicia"

\begin{tabular}{lc}
\hline ¿Quién se desempeña mejor en las siguientes actividades? & \% Ambos \\
\hline 1.-Juez/a de primera instancia & $81,4 \%$ \\
\hline 2.-Ministra/o de Corte de Apelaciones & $75,5 \%$ \\
\hline 3.-Ministro/a de Corte Suprema & $71,6 \%$ \\
\hline 4.-Secretarios & $73,9 \%$ \\
\hline 5.-Relatores & $72,7 \%$ \\
\hline 6.-Labores administrativas (oficial 10 $2^{\circ}, 3^{\circ}$, etc.; administrativos & $82,0 \%$ \\
tribunal reformado) & $77,4 \%$ \\
\hline 7.-Administradores/as y Jefes/as de Unidad & $66,1 \%$ \\
\hline 8.-Consejeros/as Técnicas & $67,7 \%$ \\
\hline 9.-Asuntos de Familia & $78,0 \%$ \\
\hline 10.-Asuntos Civiles & $79,9 \%$ \\
\hline 11.-Asuntos Penales & $78,1 \%$ \\
\hline 12.-Asuntos Laborales & $\mathbf{7 5 , 3 \%}$ \\
\hline Totales & \\
\hline
\end{tabular}

FUENTE: Elaboración propia a partir de los datos del Estudios Diagnóstico.

La Tabla 2 muestra que la gran mayoría (75,3\%) piensa que hombres y mujeres tienen un desempeño igualitario. Las actividades con menor visión igualitaria serían las de Consejería Técnica $(66,1 \%)$ y Asuntos de Familia $(67,7 \%)$, y las con mayor visión igualitaria serían la de Juez/a de primera instancia (81,4\%) y Asuntos civiles (79,9\%).

De esta forma, los datos mostraron que la gran mayoría de los miembros del PJUD entrevistados no perciben la existencia de machismo al interior de la organización, pero que paradójicamente, tendrían expectativas de género bastante igualitarias en materia de desempeño laboral (Tabla 1). Además, una fracción mayoritaria de los entrevistados cree que hombres y mujeres tienen estilos y habilidades distintas (Tabla 2).

Pero ¿Por qué hay personas que identifican mejor el machismo o tienen visiones más igualitarias que otras? Lo siguientes análisis buscan responder a esto.

\section{Análisis explicativo}

Los análisis siguientes se efectuaron con la técnica estadística de regresión lineal múltiple que permite conocer la influencia de un conjunto de variables independientes 
$X_{s}\left(X_{1}, X_{2}, X_{n} \ldots\right)$ sobre una variable dependiente $Y$. La introducción simultánea de todas las variables en un mismo modelo permite que las correlaciones 'entre' las variables Xs (también de cada $X$ con $Y$ ) sean controladas. Se utilizó el método que incorpora todas las variables simultáneamente (forced entry) sin que se busque encontrar el modelo óptimo ${ }^{7}$ como ocurre con otras técnicas ${ }^{8}$. Para seleccionar las variables independientes a incorporar en el análisis consideramos dos criterios: que correlacionaran a nivel bivariado con las variables dependientes y/o tuviesen suficiente coherencia teórica que justificara su inclusión en el modelo. La significancia fue calculada unilateralmente ${ }^{9}$ y al 10\%. Los análisis se efectuaron con 3904 casos. Dado que este trabajo está dirigido principalmente a abogados/as no nos hemos adentrado en el detalle estadístico y hemos expuesto los resultados de forma narrativa, pero las tablas que los respaldas se han anexado.

Encontramos que el conjunto de variables usadas (sociodemográficas, de escalafón, de género y contexto) logró explicar un $16 \%$ de la variabilidad en el primer modelo, un $10,2 \%$ para en el segundo y un $7,3 \%$ en el tercero. La fuerza explicativa de los modelos es baja si evaluamos estos valores desde un criterio estadístico exigente, sobre todo en los dos últimos casos. Sin embargo, debe tenerse presente que la calidad de los datos iniciales no fue óptima. Además, debemos considerar que el estado del conocimiento en esta materia (estudios estadísticos de género, en poderes judiciales latinoamericanos) es bastante deficiente. La ausencia de literatura contextualizada en este tema permite que podamos considerar esta investigación, en buena medida, como exploratoria, pero que nos permite mostrar la tendencia de que siguen los datos y avanzar en esta temática.

El análisis por bloques mostró que, en general, las variables de género (hostigamiento laboral con contenido sexual, acoso sexual, discriminación por ser hombre o mujer, etc.) y las sociodemográficas y civiles (sexo, edad, nivel educacional, tener pareja y/o hijos) fueron las que presentaron mejor poder explicativo ${ }^{10}$. Esto significa que el perfil sociodemográfico y los aspectos de género son los ámbitos que, en mayor medida, pueden dar cuenta de las representaciones de género que tiene un individuo. El escalafón seguido de las variables de contexto (pertenencia o no la CS, tamaño de la Corte, porcentaje de magistradas), aunque significativas presentaron una capacidad explicativa muy baja, cercana a nula11. Es decir, estas variables ayudarían a explicar muy poco las representaciones de género. Veamos ahora cómo se comportaron las variables individualmente y no por bloques.

Para identificar cuáles son las variables que, tomadas individualmente, más (o menos) influyen en las representaciones de género, contemplamos criterios de fuerza (mediante el coeficiente beta) y consistencia (número de modelos en los que se detectaron relaciones significativas). Mediante este procedimiento logramos identificar tres grupos principales de predictores.

El primero incorporó aquellos predictores que presentaron interrelaciones significativas en los tres modelos o en dos de los tres modelos, con fuerza moderada. Dentro del grupo, los ordenamos decrecientemente de acuerdo a su fuerza explicativa. Así, se observó que, en general, quienes perciben mayores niveles de machismo explícito, tienen una visión más igualitaria sobre el desempeño y/o tienen mayor expectativa de equidad en las relaciones laborales, serían:

7. Mayor poder explicativo con el menor número de variables.

8 La regresión secuencial, de pasos sucesivos, etc. tienden a excluir variables no significativas y mantener sólo las significativas para lograr el modelo óptimo.

9 La significancia indica que dos variables están estadísticamente relacionadas con una alta probabilidad.

10. Las primeras contribuyen a explicar las representaciones de género entre un 3.2 y $8,0 \%$, mientras que las segundas entre un $1.9 \%$ y un $6.6 \%$.

11. La variable escalafón explica entre un $0,5 \%$ y un $2,1 \%$, mientras que las de contexto, mientras que las variables de contexto, apenas explican entre un $0,1 \%$ y un $0,3 \%$. 
- Las mujeres.

- Quienes pertenecen al Escalafón primario (jueces/as y ministros/as), seguidos -en orden decreciente- de quienes pertenecen al Escalafón secundario (profesionales), al Personal a honorarios y contrata (profesionales) y, finalmente, pertenecientes al Escalafón de empleados.

- Mujeres que se han sentido discriminadas por el hecho de ser mujeres y/o personas que declaran haber presenciado discriminación hacia una mujer ${ }^{12}$.

- Hombres que no se han sentido por discriminados por ser hombres y/o personas que no han presenciado discriminación hacia hombres.

- Personas que poseen un nivel educacional más alto.

- Personas con expectativas de roles de género más igualitarias en la sociedad en general (es decir, no consideran que existan roles naturales para hombres o mujeres).

- Dada la consistencia presentada, estas variables pueden ser consideradas como predictores bastante estables que contribuirían a dar cuenta de las representaciones de género aludidas.

El segundo grupo incluye aquellos predictores que mostraron ser significativos en solo uno de los tres modelos. Decrecientemente, se observó que quienes más perciben machismo, poseen una visión más igualitaria del desempeño o una mayor visión de equidad en las relaciones laborales, serían las personas que:

Trabajan en tribunales con un mayor porcentaje de magistradas (juezas y ministras). A mayor número de juezas y ministras en una Corte, mayor es la percepción de machismo en el PJUD.

No pertenecen/No trabajan en la Corte Suprema. Quienes no trabajan en la Corte Suprema, tendrían una expectativa más equitativa en cuanto al desempeño entre hombres y mujeres.

Que trabajan en cortes de mayor tamaño. Tendrían una visión más igualitaria en cuanto a las capacidades y el desempeño entre hombres y mujeres.

Quienes tienen pareja. Tendrían una visión más igualitaria en cuanto a las capacidades y el desempeño entre hombres y mujeres.

Son más jóvenes. También tendrían una visión más igualitaria en cuanto a las capacidades y el desempeño entre hombres y mujeres.

Han realizado cursos de formación con contenido de género. Identificarían de mejor forma el machismo en el PJUD.

La fuerza de estos predictores es bastante baja, cercana a nula. Por ello, deberían considerarse como predictores en sentido estricto, sin ulteriores confirmaciones.

Finalmente, dos variables presentaron comportamientos inconsistentes. Quienes han presenciado o sido víctimas de acoso sexual en su trabajo, identificarían más el

12. La pregunta formulada fue si 'se ha sentido o presenciado' discriminación por ser mujer. En este sentido, sólo una mujer puede haberse sentido discriminada por ser mujer, pero tanto una mujer como un hombre pueden haber presenciado una situación de discriminación hacia una mujer por el hecho de ser mujer. Del mismo modo (para el caso siguiente), sólo un hombre puede haberse sentido discriminado por ser hombre, pero tanto un hombre como una mujer pueden haber presenciado discriminación hacia hombres. 
machismo en el PJUD, pero paradójicamente presentarían visiones menos equitativas en cuanto a las capacidades y desempeño entre hombres y mujeres. Además, quienes han presenciado o sido víctimas de hostigamiento laboral con contenido sexual percibirían más machismo explícito, pero paradójicamente, tendrían visiones menos equitativas en materia de género. Finalmente, "el tener hijos", no resultó ser significativa con ninguna de las variables dependientes.

Los datos muestran que, si bien se encontraron relaciones significativas, es prudente afirmar que contamos sólo con un apoyo parcial de nuestras hipótesis, puesto que la consistencia y fuerza de estas relaciones fue bastante variable, y en algunos casos, casi nula. Sin embargo, las relaciones encontradas poseen un sentido teórico coherente, del cual intentaremos da cuenta ahora.

\section{Discusión de Resultados}

\section{Discusión de los hallazgos descriptivos: Las percepciones de género}

Aunque un grupo importante tiende a presentar una visión no igualitaria en cuanto a las capacidades y desempeño entre hombres y mujeres, la mayoría tiende a tener una visión igualitaria y no sexista en estas materias. Curiosamente, esto no se condice con la identificación de machismo, ya que la gran mayoría no percibe machismo al interior del PJUD. Esto nos indicaría que la capacidad para identificar situaciones de machismo no necesariamente iría en el mismo sentido que restantes percepciones de género que consideran que mujeres y hombres tienen capacidades igualitarias de rol y desempeño. Es decir, muchas personas pueden declarar que creen en la igualdad de roles y capacidades, pero eso no necesariamente les permite reconocer o identificar situaciones de machismo en sus organizaciones. Aunque en términos de cifras el machismo o sexismo no el alarmantes, los datos pueden tener consecuencias prácticas importantes. Por ejemplo, quien debe tomar decisiones en términos de contratación y/o ascenso puede discriminar a una mujer u hombre, por creer que hay capacidades diferentes o que hay puestos que son mejor desempeñados por hombres y otros por mujeres. Además, quien no identifica la existencia de machismo, puede tener una menor disposición para contribuir a mejorar las condiciones de las mujeres por considerar que no se encuentra ante un problema real. Esto podría expresarse en no querer participar en cursos de género, o no apoyar la implementación de cursos dentro de su unidad de trabajo. Como vemos, los pensamientos de este tipo, tienen consecuencias prácticas y que pueden afectar la política de igualdad que intenta desarrollar la Secretaría Técnica de la Corte Suprema.

\section{Discusión de los hallazgos explicativos}

La baja capacidad explicativa del modelo podría explicarse en gran parte por una operacionalización y medición inicial que no fueron especialmente óptima, lo cual es frecuente cuando se trabaja con datos que no estuvieron pensados para análisis más complejos. Sin perjuicio de esto, y tal como afirmamos, el haber identificado ciertos factores influyentes con suficiente coherencia teórica -concordantes con la literatura-, nos invita a dar sentido a nuestros resultados y así comprender mejor las percepciones de género en el PJUD. En esta discusión incorporamos interpretaciones que pueden ser plausibles y coherentes teóricamente, pero que requieren de confirmaciones en futuras investigaciones.

Perfil sociodemográfico y percepciones de género

Las mujeres son quienes identifican más machismo, tienen una visión equitativa sobre los roles y el desempeño entre hombres y mujeres. Esto respondería a que 
históricamente las mujeres han sido un grupo vulnerado y han experimentado la desigualdad de género en todos los ámbitos. En primer lugar, en el ámbito laboral, si bien ha aumentado la cantidad de mujeres directivas, las posibilidades de ascenso aún son reducidas (Lamas, s.a), el salario es menor por la misma labor (Mendoza et. al, 2017; Cacciamali \& Tatei, 2013) y aún persiste el acoso laboral debido, primero, a la creencia de inferioridad de la mujer (Hernández et. al, 2015; Herrera et. al, 2013) y, segundo, a una naturalización de creencias relacionadas con los roles y capacidades esperados para las mujeres (Arena, 2016). El pertenecer a una categoría general de vida (ser mujer) que es víctima de la desigualdad, contribuiría a desarrollar representaciones de género más igualitarias y la capacidad para identificar el machismo más claramente.

El que personas con mayor nivel educacional identifiquen mejor el machismo y tengan una visión más equitativa sobre los roles y el desempeño (menos sexista), sería concordante con la literatura, dado que al mejorar el nivel socioeconómico aumenta también la percepción discriminación por género (Centro Regional de Derechos Humanos y Justicia de Género, 2017). El disponer de mejores niveles educacionales implica la adquisición de un mejor capital cultural que permite interiorizar, formalmente, contenidos y temáticas vinculadas, por ejemplo, a los derechos o la discriminación. A esto se suman experiencias informales de aprendizaje; quienes tienen mayores niveles educacionales tendrían experiencias grupales y educativas más ricas. Estas experiencias dotarían a los individuos de herramientas culturales y cognitivas más complejas para evaluar estas temáticas, eliminar prejuicios, identificar racionalmente situaciones injustas o discriminatorias, puesto que la educación es un fuerte predictor de la capacidad de las personas para elaborar razonamientos morales más complejos, lo cual es concordante con las teorías cognitivas del desarrollo moral (Sastre et. al, 1998).

Quienes tienen pareja identificarían mejor el machismo y tendrían expectativas de género más igualitarias. La experiencia de tener pareja permitiría que las personas desarrollen un mayor sentido de empatía, ya que permite que el otro conozca de mejor forma (o más cercanamente) las dificultades que enfrentan sus parejas mujeres. Este aprendizaje experiencial permitiría detectar de mejor forma la discriminación hacia las mujeres. Esta interpretación, sin embargo, presenta una limitación. El que una persona no tenga pareja, no implica que no la haya tenido en el pasado y, por lo tanto, haya podido desarrollar dicha empatía en un momento previo de su biografía. Sin embargo, es posible que la empatía actual, que se vive en el momento, tenga una fuerza mayor que una empatía desarrollada en el pasado y que hoy no está activa, ya que estos aprendizajes pueden olvidarse en el mediano o largo plazo si no son constantes en la vida de un individuo. Esta última puede ser una vía de explicación posible, pero no está testeada, y que debiese explorarse. El tener hijos, no incidiría en las percepciones de género. Existe la posibilidad de que 'el tener hijos' no incremente la empatía más de lo que aporta el tener pareja u otras experiencias y aprendizajes, lo cual también debe explorarse.

La edad apenas fue significativa en un modelo y débilmente. Esto contraría los datos obtenidos por Humanas (Centro Regional de Derechos Humanos y Justicia de Género, 2017) que señalan que a mayor edad hay representaciones de género más tradicionales y menos igualitarias. Además, contraría creencias comunes -recogidas cualitativamente- que estiman que el machismo o las visiones tradicionales de género se presentan más intensamente en personas mayores. No tenemos una explicación segura para estos resultados. Metodológicamente, la edad no fue medida 
como pregunta abierta, sino mediante tramos predefinidos. Además, la encuesta online se respondía voluntariamente y una fracción importante personas de edad más avanzada -y poco familiarizada con la tecnología- sin interés por temas de género y feminismo, pudo no responder, generando un sesgo sistemático en la muestra. Estas explicaciones posibles -no están testeadas- podrían de la ausencia de relación encontrada entre edad y representaciones. Ahora, buscando una explicación teórica, creemos que puede ocurrir que, en el ámbito jurídico, el tema de género haya penetrado transversalmente en la institución, modificando las visiones más tradicionales. También podríamos estar ante la situación de que personas mayores con creencias de género más conservadoras sean muy pocos casos -en relación a todos los que trabajan en el PJUD-, pero muy visibles (p.ej. ministros, jueces), lo cual generaría la percepción de que los mayores poseen representaciones más tradicionales y sexistas.

Estos hallazgos pueden conducir a consecuencias prácticas. Por ejemplo, permiten identificar aquellos grupos hacia los cuales pueden dirigirse campañas de sensibilización de forma focalizada, hacia hombres o personas con niveles educacionales más bajos, priorizándolos temporalmente por ser los grupos más críticos. Hallazgos de este tipo pueden ayudar a orientar programas de formación o sensibilización, ya que muestran que metodologías de enseñanzas basadas en juegos de rol o casos podrían ser efectivas, al pensar, por ejemplo, que las personas imaginen a sus parejas, madres o hermanas siendo víctimas de discriminación, acoso u hostigamiento.

\section{Escalafón y percepciones de género}

La jerarquía en el PJUD presenta matices en las percepciones de género. Primero, a medida que se desciende en la jerarquía, se identifica menos el machismo, y hay representaciones menos equitativas de género. Esto se explicaría principalmente porque el conocimiento de la temática de género ha descendido de forma vertical en la organización. Por una parte, los casos judiciales de discriminación-Zamudio, Atala, Blass-, tienen un mayor impacto en el segmento de los profesionales del Derecho al interior del PJUD, ya que supondrían un saber un poco más especializado. La Asociación Nacional de Magistradas Chilenas fue creada por juezas/ces, Defensoras/es y Fiscales/as en el 2013 para defender y promocionar los derechos de las mujeres en concordancia con el derecho y normativa nacional e internacional. Por otra parte, las iniciativas de género, tales como cursos de formación, diagnósticos, políticas (Política de género en el PJUD), se han implementado desde el poder jerárquico central (Corte Suprema). Entonces, la difusión y sensibilización en género habría ocurrido también verticalmente, desde arriba hacia abajo. Por ello, los escalafones más bajos y más alejados de la cultura de género impulsada por poder central, estarían menos sensibilizados.

Si bien, son los jueces y ministros los principales responsables de la decisión jurídica, el trato cotidiano con usuarios y dentro del mismo PJUD se da cotidianamente con funcionarios de otros escalafones. Por ello, estos antecedentes permitirían focalizar políticas de género al mostrarnos en cuáles escalafones la sensibilidad de género se encuentra menos interiorizada.

Variables de género y percepciones de género

Quienes han sido víctimas o testigos de discriminación por ser mujer, identifican en mayor medida la presencia de machismo y tienen expectativas de género más igualitarias. La vivencia de discriminación por maternidad, cuidado de hijos, edad fértil (Arredondo et al, 2013; Álvez, 2008), el recibir menos salario por el mismo 
desempeño y cargo (Mendoza et. al, 2017; Cacciamali \& Tatei, 2013) o las dificultades para ascender influirían en la percepción que el sujeto que se forma del entorno (García, 2011). Desde sus propias experiencias, las personas verían confirmados postulados básicos del enfoque de género, como el machismo, el patriarcado, los estereotipos. En cambio, quienes han sido víctimas o testigos de discriminación por el hecho de ser hombres, identificarían en menor grado prácticas machistas y tendrían visiones menos igualitarias sobre el género. Experimentar tratos que no son igualitarios y que perjudican a los hombres, influiría en influiría en la percepción de las relaciones de género en su entorno y a poner en tela de juicio postulados básicos del enfoque de género (el patriarcado, el machismo, la dominación masculina), ya que su vivencia adversa estaría en contradicción con estos postulados.

La vivencia (como víctima o testigo) de hostigamiento laboral y/o acoso sexual laboral presentó inconsistencias; solo mostraron relación con el machismo explícito. El hostigamiento y acoso se basan en la creencia de que las mujeres son el sexo débil y vulnerable (Arredondo et. al, 2013). Vivir o ser testigo de estas prácticas, llevaría a identificar la existencia una cultura machista por contar con evidencia personal para confirmar la existencia de los postulados de género (patriarcado, sexismo, machismo, etc.) en el entorno. Sin embargo, paradójicamente, el haber sido víctima o presenciado acoso u hostigamiento llevaría a que los individuos tengan una visión de género menos igualitaria. No tenemos una explicación teórica para estos resultados, puesto que no concuerdan con la literatura, y deberían ser explorados con más detalle en futuras investigaciones.

El poseer expectativas equitativas sobre los roles de género permitiría comprender y tener una mejor sintonía con algunos de los postulados básicos del enfoque de género. Así, el contar con una creencia general de que en la vida social no existen roles naturales de género -sino que éstos son construcciones socioculturales-, influiría positivamente en la capacidad para identificar prácticas machistas y en el tener una visión más igualitaria (y no sexista) de los roles de género en el ámbito laboral. De esta manera, Un conocimiento más general (visión de la sociedad y roles como construcciones sociales), permite una mejor comprensión de los ámbitos particulares (roles en ámbito laboral).

La formación en género no tendría mayor influencia sobre las representaciones de género (solo en un modelo y muy débilmente). Esto puede tener una explicación metodológica, puesto que se trabajó con preguntas de filtro (realizó un curso), y luego, solo al grupo que respondió afirmativamente se le consultó si había tenido "contenido de género". Ello pudo tener alguna incidencia, ya que a quienes son respondieron, no se les presentó la opción. Sin embargo, creemos que la explicación más coherente es de tipo contextual. Hoy no existe obligatoriedad de realizar cursos con contenido de género en la Academia Judicial, jueces y funcionarios pueden elegir sus ámbitos de especialización. De esta forma, los cursos en temáticas de género serían elegidos por quienes ya están interesados o poseen una sensibilidad previa (incluso conocimientos) favorable hacia dichos temas. Los cursos proporcionarían conocimiento, pero la actitud favorable sería previa a la formación. En cambio, quienes no tienen interés en estos temas o los rechazan por tener una visión más tradicional, simplemente, no escogerían formarse en género. 
Estos hallazgos pueden tener una utilidad práctica. Muestra que una sensibilización o formación en género que utilice ejemplos o casos concretos puede ser más efectiva. Además, muestra que, tal vez, la obligatoriedad en la formación de género y/o los incentivos para formarse en género, podrían ser necesario. También, nos indica que la formación en género enfocada en ámbito específico de trabajo (p.ej. legislación y género, discriminación y ley), puede ser menos eficaz si no va acompañada de contenidos sociológicos o antropológicos más amplios que proporcionen una visión más profunda acerca de la idea de que las relaciones humanas y el género no son 'dados', sino que son realidades socialmente construidas, cambiantes y diversas.

Variables de contexto y percepciones de género

La mayor presencia de magistradas contribuiría levemente a que se perciba menos machismo explícito en el PJUD. La presencia de más mujeres en cargos de jefatura podría llevar a que las acciones machistas se vean inhibidas en la unidad de trabajo y que efectivamente haya menos machismo. Además, la experiencia de trabajar en ambientes más heterogéneos, con una alta composición femenina, podría eventualmente conducir al desarrollo de una cultura de mayor respeto, donde el machismo comienza a ser eliminado como práctica, ya que en su mayoría son juezas las que han incorporado el enfoque de género. . Desde el ángulo de los enfoques teóricos del conflicto, la incorporación de los temas de género y feminismo en la organización judicial, pudo agudizar el conflicto hombre-mujer. La mayor presencia de mujeres no influiría en el desarrollo de una visión más igualitaria sobre los roles y capacidades de hombres y mujeres. De esta forma, pensamos que la mayor presencia de magistradas, tendría una influencia positiva en la conducta, pero no en las creencias profundas de género.

Quienes trabajan en la Corte Suprema tendrían visiones menos igualitarias en lo que respecta a las capacidades entre hombres y mujeres para desempeñarse en el ámbito jurídico. Esto no concuerda con nuestra hipótesis (esperábamos lo opuesto), ya que las políticas de género se han difundido vertical y descendentemente desde la Corte Suprema (centro de poder) hacia otras cortes (periferia). El hallazgo, sin embargo, muestra que la creencia de que hombres son buenos para ciertas tareas o materias de derecho, y mujeres para otras, estaría más arraigada el poder central. Posiblemente, la Corte Suprema mantiene una visión un poco más tradicional y conservadora acerca del sistema sexo-género en comparación a otras cortes. El pertenecer a la Corte no se relacionaría con los otros ámbitos de las representaciones de género.

El tamaño de la Corte, se relacionaría con las representaciones de género, aunque débilmente. Las cortes de menor tamaño tendrían una visión levemente menos equitativa respecto a las capacidades y estilos entre hombres y mujeres. Esto podría explicarse porque los grupos más pequeños (posiblemente pertenecientes a zonas con menos habitantes), tienden a ser más homogéneos, unidos por creencias comunes y tradicionales. En cambio, los colectivos más grandes, tienden a ser más diversos, con vínculos sociales más débiles y con menor apego a la tradición, pudiendo abrirse más a cuestionar la convención social. No se encontraron relaciones entre el tamaño de la Corte con el machismo y la visión de desempeño.

Estos resultados nos muestran que, tal vez, una mayor presencia de mujeres en las cortes podría contribuir levemente a reducir las prácticas machistas. Los hallazgos también nos sugieren que las políticas podrían focalizarse en la administración central (Corte Suprema). 


\section{Conclusiones}

Nuestro estudio se sitúa dentro de los pocos que realizan investigaciones de empíricas de naturaleza compleja en género y justicia. En este sentido, posee una naturaleza exploratoria, pero innovadora. De todas maneras, ello obliga a enfrentarse a dificultades metodológicas, que en el caso concreto resultaron de haber usado datos secundarios y de algunos problemas de medición que pudieron afectar nuestros hallazgos. Como consecuencia, las relaciones encontradas no siempre fueron consistentes y, en general, presentaron una capacidad explicativa baja. Un hallazgo entonces, es que futuras investigaciones de este tipo son posibles, pero ellas debiesen orientarse a contrastar los hallazgos propuestos en esta investigación, incorporando algunas mejoras metodológicas.

En cuanto a lo sustancial, esta investigación demuestra que, a pesar de los esfuerzos realizados por el poder Judicial en incorporar enfoques de género, los problemas de género y discriminación persisten. Ello refleja que las creencias de género son esferas de la cultura fuertemente arraigadas. En este sentido, es pertinente recordar que la Política de Género y no Discriminación del PJUD es del 2018, pero dichos esfuerzos datan desde el año 2012, luego del resultado del caso Atala.

El compromiso del Estado chileno para avanzar en un modelo de justicia cada vez más inclusivo y coherente con la normativa nacional e internacional, no puede desmarcarse de una comprensión más profunda del fenómeno del género en quienes ejercen las labores de justicia. Sin este enfoque, discriminaciones pueden igualmente originarse, arriesgando el Estado incumplir las obligaciones en Derechos Humanos a las que se ha comprometido tanto en el ámbito internacional como regional.

Esta investigación también nos ayuda a situar con mayor profundidad los factores que influyen en las representaciones de género en la organización judicial al identificar el modo en que éstas se relacionan con determinadas variables. Así, los hallazgos nos revelaron que en diversa medida, los aspectos sociodemográficos, el escalafón del individuo, las variables de género e institucionales influyen en las percepciones de género, lo cual contribuye a una mejor comprensión del fenómeno e, incluso, permite orientar ciertas acciones, tales como focalizar la capacitación e identificar estrategias formativas en género y diversidad.

\section{Referencias}

Academia Judicial. (2016): "Reporte Academia Judicial año 2013-2015". Disponible en: http://www.academiajudicial.cl/LaAcademia.aspx?id menu=98. Fecha de consulta 24 de Octubre 2018.

Álvez, Amaya (2012): “El Post-Natal parental creado por la ley 20.545: Escrutinio constitucional a la limitación de la garantía de igualdad". Anuario de Derecho Público UDP, pp. 217- 234

Arena, Federico (2016): “Los estereotipos normativos en la decisión judicial. Una exploración conceptual". Revista de derecho, Vol. XXIX Nº 1: pp. 51-75.

Arredondo, Florina; Velázquez, Luz \& De La Garza, Jorge (2013): "Políticas de diversidad y flexibilidad laboral en el marco de la responsabilidad empresarial. Un análisis desde la perspectiva de género". Estudios Gerenciales, Vol. 29: pp. 161-166. 
Arriagada, Irma (2005): "Dimensiones de la pobreza y políticas desde una perspectiva de género". Revista CEPAL, Vol. 85: pp. 101-113.

Asociación De Magistradas Chilenas MACHI. (2015): Recomendaciones para el abordaje de una política de género en el Poder Judicial Chileno. (Santiago de Chile, Comisión de Derechos Humanos y Género de la Asociación Nacional de Magistrados).

Asociación De Magistradas Chilenas MACHI. (2018): "Quienes Somos". Disponible en: http://www.magistradaschilenas.cl/quienes-somos/. Fecha de consulta 24 de Octubre 2018.

ATALA RIFFO Y NIÑAS VS CHILE. Corte Interamericana de Derechos Humanos. Sentencia del 24 de Febrero de 2012. Serie C N²39.

Benavente, María Cristina \& Vergara, Claudia. (2006): Sexualidad en hombres y mujeres. Diversidad de miradas. (Santiago de Chile, FLACSO).

Bruel Dos Santo, Teresa. (2008): "Representaciones sociales de género: Un estudio psicosocial acerca de lo masculino y lo femenino". Tesis Doctoral. Facultad de Psicología, Universidad Autónoma de Madrid. Disponible en: https://repositorio. uam.es/bitstream/handle/10486/3965/27615 bruel dos santos teresa cristina.pdf?sequence=1. Fecha de consulta 26 de Octubre 2018

Cacciamali, María Cristina. \& Tateti, Fábio. (2013): "Género y salarios de la fuerza de trabajo calificada en Brasil y México". Revista problemas del desarrollo, Vol. 172 $N^{\circ} 4$ : pp. 53- 79 .

Centro Regional de Derechos Humanos y justicia de género, CORPORACIÓN HUMANAS. (2017): "Percepciones de la mujeres sobre su situación y condiciones de vida en Chile.DuodécimaEncuestaNacional".Disponiblehttp://www.humanas.cl/wp-content/uploads/2017/12/ENCUESTA-HUMANAS-2017-VERSI\%C3\%93N-FINALNOV.pdf. Fecha de consulta 25 de Octubre de 2018.

CEPAL, Observatorio de igualdad de Género de América Latina y el Caribe. (2017): "Poder Judicial: porcentaje de mujeres ministras en el máximo tribunal de justicia o corte suprema". Disponible en: https://oig.cepal.org/es/indicadores/poder-judicial-porcentaje-mujeres-ministras-maximo-tribunal-justicia-o-corte-suprema. Fecha de consulta 26 de Octubre de 2018

CEPAL, Observatorio de igualdad de Género de América Latina y el Caribe. (2016): “Tiempo Total de Trabajo". Disponible en: https://oig.cepal.org/es/indicadores/ tiempo-total-trabajo. Fecha de consulta 26 de Octubre de 2018

CEPAL. (2007): "Cohesión Social. Inclusión y sentido de pertenencia en América Latina y el Caribe". Secretaria General Iberoamericana: Santiago de Chile. Disponible en: https://repositorio.cepal.org/bitstream/handle/11362/2812/2/S2007000 es.pdf. Fecha de consulta 26 de Octubre de 2018

Chaves, Julia (2004): “Perspectiva de género" (México, UNAM-Plaza y Valdés) 
Corte Interamericana De Derechos Humanos (CORTE IDH): "Identidad de género e igualdad y no discriminación a parejas del mismo sexo. Opinión consultiva OC24/17 Solicitada por la República de Costa Rica (24 de Noviembre 2017). Disponible en: https://www.refworld.org.es/docid/5a5d311f4.html. Fecha de consulta 02 de Enero 2019.

De Barbieri, Teresita. (1993): "Sobre la categoría de género. Una introducción teórico-metodológica". Debates en sociología, Vol. 18: pp. 145-169.

Diario LA TERCERA (2016): "Presencia femenina en directorios de empresas públicas bordeó el 30\%". Disponible en: http://www.pulso.cl/economia-dinero/presencia-femenina-en-directorios-de-empresas-publicas-bordeo-el-30-en-2015/. Fecha de consulta 25 de Octubre de 2018.

Dirección de Estudios Corte Suprema (2016): "Proyecto de Estudio Diagnostico de la perspectiva de igualdad de Género en el Poder Judicial Chileno". Documento realizado por Management \& Research Chile. Disponible en: http://secretariadegenero.pjud.cl/images/documentos/Estudio Igualdad de G nero y No Discriminaci n Final.pdf. Fecha de consulta 12 de Junio 2018

Etchezahar, Edgardo \& Ungaretti, Joaquín. (2014): “Woman Stereotypes and Ambivalent Sexism in a Sample of Adolescents from Buenos Aires". Jounal of Behaviour Health \& Social Issues, Vol. 6 N¹: pp. 87-94.

Expansión Datos Macro (2016). "Chile. Índice Global de la Brecha de Género”. Disponible en: https://datosmacro.expansion.com/demografia/indice-brecha-genero-global/chile. Fecha de Consulta 16 de Septiembre 2018

Facio, Alda. (s.a). Feminismo, Género y Patriarcado. Lectura de apoyo 1.Disponible en: http://catolicasbolivia.org/wp-content/uploads/2017/09/trab.-feminismo-genero-y-patriarcado.pdf. Fecha de consulta 10 de Octubre 2018.

Fuller, Norma. (2012): "Repensando el Machismo Latinoamericano". Masculinities and social change, Vol. $1 \mathrm{~N}^{\circ} 2$ : pp. 114-133.

GABRIELA BLASS Y SU HIJA C.B.B. Comisión Interamericana de Derechos Humanos. Informe de solución amistosa $N^{\circ}$ 138/18, de la petición 687-11. Chile, 21 de noviembre de 2018.

García, Cruz. (2011): “La escritura de la percepción de la inseguridad pública”. Liberabit, Vol. $18 \mathrm{~N}^{\circ} 1$ : pp. 37-44.

Gauché, Ximena; Muñoz, Carlos; Bustos, Cecilia \& Álvez, Amaya. (2016): “Participación política de las mujeres en Chile y sus oportunidades, en la percepción de estudiantes de primer año de universidad. El caso de la Universidad de Concepción". Revista Chilena de Derecho y Ciencia Política, Vol. 7 №2: pp. 157-185.

GOBIERNO DE CHILE, Ministerio de Eduación. (2018): “Orientaciones para promover la igualdad de género en Educación Parvularia". Subsecretaría de Educación Parvularia Disponible en: https://parvularia.mineduc.cl/wp-content/uploads/ sites/34/2018/03/Igualdad-de-G\%C3\%A9nero.pdf. Fecha de consulta 29 de Octubre 2018. 
Hernández, Claudia; Jiménez, Martha \& Guadarrama, Eduardo. (2015): “La percepción del hostigamiento y acoso sexual en mujeres estudiantes en dos instituciones de educación superior". Revista de la Educación Superior, Vol. 176: pp. 63- 82.

Herrera, Antonio; Pina, Afronditi; Herrera, Carmen \& Expósito, Francisca. (2014): "¿Mito o realidad? Influencia de la ideología en la percepción social del acoso sexual". Anuario de Psicología Jurídica, Vol. 24: pp. 1-7.

Instituto Nacional de Estadísticas, INE (2013): "Síntesis de Resultados CENSO 2012". Disponible en: http://www.iab.cl/wp-content/files $\mathrm{mf} /$ resumencenso 2012.pdf. Fecha de consulta 28 de Octubre 2018.

Instituto Nacional De Las Mujeres, (2007): “ABC del género en la administración pública". México, DF. Disponible en: http://cedoc.inmujeres.gob.mx/documentos download/100903.pdf. Fecha de consulta 03 Noviembre 2018.

Jociles, María José. (2001): “El estudio sobre las masculinidades. Panorama general". Gazeta de Antropología, Vol. 17 N²7: pp. 1-14.

Lamas, Marta (1999): Usos, dificultades y posibilidades de la categoría género. (Mexico, Ed. Universidad Autónoma del Estado de México)

Lamas, Marta. (s.a). "La perspectiva de género". Revista de educación y cultura, Vol. 47: pp. 1-8.

LEY N 19023 (1991), Crea el Servicio Nacional de la Mujer.

LEY N² 20.820 (2015), Crea el Ministerio de la Mujer y la Equidad de Género.

LEY N² 20.840 (2015), Sustituye el sistema electoral binominal por uno de carácter proporcional inclusivo y fortalece la representatividad del Congreso Nacional.

LEY N² 20.891 (2016), Perfecciona el permiso postnatal parental y el ejercicio del Derecho a Sala Cuna para las funcionarias y funcionarios públicos.

LEY N ${ }^{\circ} 21,063$ (2017), Crea un seguro para el acompañamiento de niños y niñas que padezcan las enfermedades que indica, y modifica el Código del Trabajo para estos efectos.

LEY N²1.030 (2017), Regula la Despenalización de la Interrupción Voluntaria del embarazo en tres causales.

LEY N²1.129 (2019), Modifica diversos cuerpos legales a fin de establecer fuero maternal a las funcionarias de las Fuerzas Armadas, de orden y seguridad pública en las condiciones que indica.

LEY N² 21120 (2018), reconoce y da protección al Derecho a la Identidad de Género.

LEY N¹9.591 (1998), Modifica el código del trabajo en materia de protección a la maternidad.

LEY N²0.005 (2005), Tipifica y sanciona el Acoso Sexual. 
LEY N²0.066 (2005), Ley de Violencia Intrafamiliar.

LEY N²0.166 (2007), Extiende el derecho de las madres trabajadoras a amamantar a sus hijos aun cuando no exista sala cuna.

LEY N²0.255 (2008), que estableció la reforma previsional y otorgo a mujeres un bono por hijo/a nacido vivo.

LEY N²0.348 (2009), Otorga derecho a sala cuna al trabajador/a.

LEY N²0.348 (2009), Resguarda el derecho a la igualdad en las remuneraciones entre hombres y mujeres.

LEY N²0.418 (2010), que fija normas sobre información, orientación y prestaciones en materia de regulación de la fertilidad, 2010.

LEY N²0.480 (2010), Modifica el Código Penal y la Ley sobre Violencia Intrafamiliar.

LEY N²0.533 (2011), que faculta a las matronas para recetar anticonceptivos.

LEY N²0.545 (2011), que modifica las normas de protección a la maternidad e incorpora el permiso de posnatal paternal.

LEY N²0.595 (2012), crea el Ingreso Ético Familiar para las familias de pobreza extrema y el subsidio de empleo de la mujer.

LEY N²0.609 (2012), que establece medidas contra la discriminación.

LEY N²0.830 (2015), Crea Acuerdo de Unión Civil.

Lorenc, Federico (2014): “Émile Durkheim y la Teoría Sociológica de la Acción”. Andamios, Vol. 11 N²6: pp. 299-322.

Macionis, Jhon \& Plummer, Ken. (2007): Sociología. Pearson Prentice Hall, (Madrid, $3^{\circ}$ Edición).

Martínez, Carlos; Vicent, Lucia. (2018): "Una Selección de Organizaciones Feministas". FUHEM Ecosocial. Disponible en: http://www.fuhem.es/ecosocial/noticias.aspx$\underline{? V=9537 \& n=0}$. Fecha de recuperacion 05 noviembre 2018.

Mendoza, Miguel; Cardero, María Elena; Ortiz, Alejandra. (2017): "Algunos hechos estilizados y explicativos sobre el diferencial y la discriminación salarial por sexo en México, 1987-2015". Investigación Económica, Vol. LXXVI №301: pp. 103-135.

Morales, María. (2016): “Aproximación al acoso laboral. Desde la legislación comparada". Boletín Mexicano de Derecho Comparado, Vol. 147: pp. 71-98.

Muñoz, Fernando (2015): "Análisis crítico de la jurisprudencia sobre Ley Zamudio entre 2012 y 2015", Revista de Derecho (Valdivia), Vol. XXVIII, Nº. 2: pp. 1-23.

Osorio, John. (2015): “Esa extraña idea generalizada acerca de la inferioridad de las mujeres". Revista CES Derecho, Vol. 6 N²: pp. 133-137. 
Poder Judicial De Chile (2018). "Política de igualdad de género y no discriminación". 02 de Febrero 2018.

Poder Judicial De Chile (2018): Institucional. Disponible en: www.pjud.cl. Fecha de consulta 05 de Octubre 2018.

Principios de Yogyakarta (2016): "sobre la aplicación de la legislación internacional de derechos humanos en relación con la orientación sexual e identidad de género" Preámbulo.

Programa de las Naciones Unidas para el Desarrollo (PNUD), (2016): “Informe sobre desarrollo Humano 2016. Panorama general". Disponible en: http://hdr.undp. org/sites/default/files/HDR2016_SP Overview_Web.pdf. Fecha de consulta 17 de ocrubre de 2018.

Rodríguez, Alfredo. \& Costa, Ana. (2013): "Morality of social bonds and moral education in Durkheim". Educación XXI, Vol. 16 N²: pp. 115-134.

Saldivia, Laura. (s.a): "Reexaminando la construcción binaria de la sexualidad". Disponible en: https://law.yale.edu/system/files/documents/pdf/Student Organizations/SELA09 Saldivia Sp PV.pdf. Fecha de consulta 17 de noviembre 2018.

Sastre, Genoveva. Moreno, Montserrat \& Timón, Mónica. (1998). "Razonamiento moral y educación". Educar, Vol. 22 N²3: pp. 155-170.

Secretaría Técnica de Género y no Discriminación, PJUD (2018): “Proyectos". Disponible en: http://secretariadegenero.pjud.cl/index.php/proyectos. Fecha de consulta 28 de noviembre 2018.

Secretaría Técnica de Género y no Discriminación, PJUD (2018): "Quienes Somos". Disponible en: http://secretariadegenero.pjud.cl/index.php/quienes-somos. Fecha de consulta 28 de noviembre 2018.

Trejo, Karina (2017). “Conceptualización de los derechos humanos desde la perspectiva de género en relación con la reforma laboral". Revista Latinoamericana del Derecho Social, Vol. 24 N¹: pp. 133-172.

Vargas, Armando; Herrera, Ana \& Perrotini, Ignacio. (2015): La participación laboral femenina y el uso del tiempo en el cuidado del hogar en México". Contaduría y administración, Vol. 60: pp. 651-662. 
Anexos: Modelos de Regresión Múltiple

Tabla 1. Factores que influyen en el machismo explícito percibido en el PJUD

\begin{tabular}{|c|c|c|c|c|c|}
\hline \multirow{2}{*}{$\begin{array}{l}\text { Variables } \\
\text { Perfil sociodemográfico }\end{array}$} & \multicolumn{5}{|c|}{ Machismo explícito Percibido (Modelo 1) } \\
\hline & \multicolumn{2}{|l|}{ Zero-r } & \multicolumn{3}{|c|}{ B (Regresión) } \\
\hline Sexo (Mujer=1, Hombre=0) & $.225^{*}$ & $172^{\cdots *}$ & & & \\
\hline Edad & $-.039^{* *}$ & ,000 & & & \\
\hline Nivel Educacional & $.088^{* *}$ &, $032^{*}$ & & & \\
\hline Pareja $(S i ́=1$, No=0) & $-.076^{* *}$ &,- 012 & & & \\
\hline Hijos (Sí=1, No=0) & $.060^{* *}$ &,- 026 & & & \\
\hline \multicolumn{6}{|l|}{ Escalafón de pertenencia } \\
\hline Primario (variable de referencia) & $.042^{* *}$ & & - & & \\
\hline Secundario & -.011 & &,$- 052^{* *}$ & & \\
\hline Empleados & $-.074^{* *}$ & &,$- 095^{* *}$ & & \\
\hline Contrata + Honorarios & $.035^{*}$ & &,$- 036^{\dagger}$ & & \\
\hline \multicolumn{6}{|l|}{ Variables de género } \\
\hline Hostigamiento Laboral con contenido Sexual & $.230^{* *}$ & & & $.124^{* * *}$ & \\
\hline Acoso sexual en el lugar de trabajo $\left(S i ́=1, N_{0}=0\right)$ & $.157^{* *}$ & & &, $059^{\cdots \cdots}$ & \\
\hline Expectativas equitativas de roles de género (sociedad) & $.048^{* *}$ & & & .017 & \\
\hline Formación en Género & $.026^{*}$ & & &, $022^{\dagger}$ & \\
\hline \multicolumn{6}{|l|}{ Discriminación por ser: } \\
\hline Mujer (Sí=1, No=0) & $.295^{*}$ & & &, $219^{* * *}$ & \\
\hline Hombre (Sí=1, No=0) & -.004 & & &,$- 039^{* *}$ & \\
\hline \multicolumn{6}{|l|}{ Unidad de pertenencia } \\
\hline Pertenencia a la Corte Suprema $(\mathrm{Si}=1, \mathrm{No}=0)$ & $.038^{* *}$ & & & &,- 003 \\
\hline Tamaño de la Corte & -.011 & & & &,- 006 \\
\hline Presencia Magistradas en la unidad de trabajo & $-.045^{* *}$ & & & &,$- 059^{* *}$ \\
\hline Constante/Error Estándar & & & & $2,203 /$ & 0,163 \\
\hline$R^{2}$ ajustado & & 0,066 & 0,071 & 0,156 & 0,159 \\
\hline p-valor (significancia) & & 0,000 & 0,000 & 0,000 & 0,001 \\
\hline
\end{tabular}

$\dagger p<.10$ (significancia marginal) ${ }^{*} p<.05{ }^{* *} p<.01^{* * *} p<.001$ (unilateral) 
Tabla 2. Visión sobre el desempeño y las capacidades igualitarias en ámbito judicial

Variables

Visión sobre el desempeño y las capacidades igualitarias en ámbito judicial (Modelo 2)

\begin{tabular}{|c|c|c|c|c|c|}
\hline \multirow{2}{*}{$\begin{array}{l}\text { Perfil sociodemográfico } \\
\qquad \text { Sexo (Mujer }=1, \text { Hombre }=0)\end{array}$} & \multirow{2}{*}{$\frac{\text { Zero-r }}{.186^{* \prime}}$} & \multicolumn{3}{|c|}{ B (Regresión) } & \\
\hline & &, $167^{* *}$ & & & \\
\hline Edad &,$- 045^{*}$ &,$- 027^{*}$ & & & \\
\hline Nivel Educacional & $.145^{*}$ &, $061^{\cdots *}$ & & & \\
\hline Pareja (Sí=1, No=0) & .015 &, $038^{* *}$ & & & \\
\hline Hijos (Sí=1, No=0) & -.013 &, 003 & & & \\
\hline \multicolumn{6}{|l|}{ Escalafón de pertenencia } \\
\hline Primario (variable de referencia) & \multicolumn{2}{|l|}{$.078^{* *}$} & \multicolumn{2}{|l|}{-} & \\
\hline Secundario & \multicolumn{2}{|l|}{$.051^{* *}$} & \multicolumn{2}{|l|}{,$- 064^{\cdots *}$} & \\
\hline Empleados & \multicolumn{2}{|l|}{$-.108^{* *}$} & \multicolumn{2}{|l|}{,$- 182^{* * *}$} & \\
\hline Contrata + Honorarios & \multicolumn{2}{|l|}{-.016} & \multicolumn{2}{|l|}{,$- 141^{* * *}$} & \\
\hline \multicolumn{6}{|l|}{ Variables de género } \\
\hline Hostigamiento Laboral con contenido Sexual & \multicolumn{3}{|l|}{-.010} & \multicolumn{2}{|l|}{,$- 044^{*}$} \\
\hline Acoso sexual en el lugar de trabajo $\left(S i ́=1, N_{0}=0\right)$ & \multicolumn{3}{|l|}{-.018} & \multicolumn{2}{|l|}{,$- 035^{*}$} \\
\hline $\begin{array}{r}\text { Expectativas equitativas de roles de género } \\
\text { (sociedad) }\end{array}$ & \multicolumn{3}{|l|}{$180^{* *}$} & \multicolumn{2}{|l|}{, $166^{\cdots *}$} \\
\hline Formación en Género & \multicolumn{3}{|l|}{-.014} & \multicolumn{2}{|l|}{,- 011} \\
\hline \multicolumn{6}{|l|}{ Discriminación por ser: } \\
\hline Mujer (Sí=1, No=0) & $.108^{* *}$ & & \multicolumn{3}{|c|}{, $075^{* *}$} \\
\hline Hombre $\left(S_{i}=1, N_{0}=0\right)$ & $-.081^{* *}$ & & \multicolumn{3}{|c|}{,$- 080^{\cdots *}$} \\
\hline \multicolumn{6}{|l|}{ Unidad de pertenencia } \\
\hline Pertenencia a la Corte Suprema $\left(S i ́=1, N_{0}=0\right)$ & .009 & & & & .007 \\
\hline Tamaño de la Corte & $.032^{*}$ & & & & $.039+$ \\
\hline Presencia de magistradas en la unidad de trabajo. & .015 & & & &, 030 \\
\hline Constante/Error Estándar & & & & & $3,060 / 0,136$ \\
\hline$R^{2}$ ajustado & & 0,051 & 0,065 & 0,102 & 0,102 \\
\hline p-valor (significancia) & & 0,000 & 0,000 & 0,000 & 0,000 \\
\hline
\end{tabular}


Tabla 3. Expectativas sobre desempeño igualitario entre hombres y mujeres para labores de justicia

\begin{tabular}{|c|c|c|c|c|c|}
\hline \multirow[b]{2}{*}{ Perfil sociodemográfico } & \multicolumn{5}{|c|}{$\begin{array}{c}\text { Expectativas sobre desempeño igualitario } \\
\text { entre hombres y mujeres para labores de } \\
\text { justicia (Modelo 3) }\end{array}$} \\
\hline & \multirow{2}{*}{$\frac{\text { Zero-r }}{, 098^{* *}}$} & \multirow{2}{*}{, $072^{\cdots}$} & \multicolumn{2}{|c|}{ B (Regresión) } & \\
\hline Sexo (Mujer=1, Hombre=0) & & & & & \\
\hline Edad &,- 014 &,- 004 & & & \\
\hline Nivel Educacional &, $121^{* *}$ &, $040^{*}$ & & & \\
\hline Pareja $\left(S i ́=1, N_{0}=0\right)$ &, 002 &,- 004 & & & \\
\hline Hijos $(S i ́=1$, No=0) &, 002 &, 010 & & & \\
\hline \multicolumn{6}{|l|}{ Escalafón de pertenencia } \\
\hline Primario (variable de referencia) & \multicolumn{2}{|l|}{, $122^{* *}$} & \multicolumn{2}{|l|}{-} & \\
\hline Secundario & \multicolumn{2}{|l|}{, $069^{* *}$} & \multicolumn{2}{|l|}{,$- 071^{* * *}$} & \\
\hline Empleados & \multicolumn{2}{|l|}{,$- 114^{*}$} & \multicolumn{2}{|l|}{,$- 224^{* * *}$} & \\
\hline Contrata + Honorarios & \multicolumn{2}{|l|}{,$- 038^{* *}$} & \multicolumn{2}{|l|}{,$- 158^{* * *}$} & \\
\hline \multicolumn{6}{|l|}{ Variables de género } \\
\hline Hostigamiento Laboral con contenido Sexual & \multicolumn{2}{|l|}{, 014} & \multicolumn{3}{|c|}{,- 002} \\
\hline Acoso sexual en el lugar de trabajo $\left(S i ́=1, N_{0}=0\right)$ & \multicolumn{2}{|l|}{,$- 041^{* *}$} & \multicolumn{3}{|c|}{,$- 064^{* * *}$} \\
\hline $\begin{array}{r}\text { Expectativas equitativas de roles de género } \\
\text { (sociedad) }\end{array}$ & \multicolumn{2}{|l|}{, $175^{* *}$} & \multicolumn{3}{|c|}{, $169^{* * *}$} \\
\hline Formación en Género & \multicolumn{2}{|l|}{,$- 031^{*}$} & \multicolumn{3}{|c|}{,- 013} \\
\hline \multicolumn{6}{|l|}{ Discriminación por ser } \\
\hline Mujer (Sí=1, No=0) & \multicolumn{2}{|l|}{, $065^{* *}$} & \multicolumn{3}{|c|}{, $044^{* *}$} \\
\hline Hombre $(\mathrm{Si}=1, \mathrm{No}=0)$ & \multicolumn{2}{|l|}{,$- 043^{* *}$} & \multicolumn{3}{|c|}{,$- 029^{*}$} \\
\hline \multicolumn{6}{|l|}{ Unidad de pertenencia } \\
\hline Pertenencia a la Corte Suprema $\left(S i ́=1, N_{0}=0\right)$ &,$- 059^{* *}$ & & & &,$- 054^{*}$ \\
\hline Tamaño de la Corte &, 022 & & & &, 011 \\
\hline Presencia de Magistradas en la unidad de trabajo & $.029^{*}$ & & & & .030 \\
\hline Constante/Error Estándar & & & & & $8,946 / 0,61$ \\
\hline $\mathrm{R}^{2}$ ajustado & & 0,019 & 0,040 & 0,072 & 0,073 \\
\hline p-valor (significancia) & & 0,000 & 0,000 & 0,000 & 0,000 \\
\hline
\end{tabular}

$\dagger p<.10$ (significancia marginal) ${ }^{*} p<.05{ }^{* *} p<.01{ }^{* * *} p<.001$ (unilateral) 